\title{
Diagnostic and interventional digital pancreatoscopy as an "all-in-one" approach in chronic pancreatitis: a case report
}

A 77-year-old man was admitted with severe abdominal pain. His laboratory tests and abdominal ultrasound revealed an acute-on-chronic pancreatitis, with a dilated main pancreatic duct (MPD) up to $10 \mathrm{~mm}$ and multiple stones causing the symptoms ( $\triangleright$ Video 1 ).

The patient was therefore scheduled to undergo endoscopic retrograde cholangiopancreatography (ERCP) of the MPD, and this confirmed the ultrasound findings. In addition, a high grade stenosis of the MPD was observed in the corpus and a 0.018-inch guidewire could not be passed beyond this under fluoroscopy guidance. On the basis of these findings, a digital single-operator pancreatoscopy (SOP; SpyGlass DS, Boston Scientific, USA) was performed. The pancreatoscope was negotiated into the MPD verifying the presence of the intraductal stones and that the stenosis of the MPD was caused by a membranous inflammatory scar ( $>$ Video 1$)$.

As an incidental finding, a villous polypoid lesion of $3 \mathrm{~mm}$ was seen within the MPD in the pancreatic head. Under direct visualization, several biopsies were taken using forceps (SpyBite; Boston Scientific). Subsequently, electrohydraulic lithotripsy of the stones was performed and the fragments were retrieved. Under pancreatoscopic guidance, the stenosis was intubated with a guidewire and dilated to $6 \mathrm{~mm}$, following which a pancreatic plastic stent $(10 \mathrm{Fr} \times 10 \mathrm{~cm})$ was inserted. The patient was free of symptoms by 2 days after the intervention.

Histology of the lesion revealed a pancreatic intraepithelial neoplasia with severe nuclear atypia (PanIN-3; a premalignant condition). Therefore, the patient underwent a pylorus-preserving Whipple's procedure without complications. The final histology was confirmed as PanIN-3.

In conclusion, despite the use of high resolution magnetic resonance imaging,

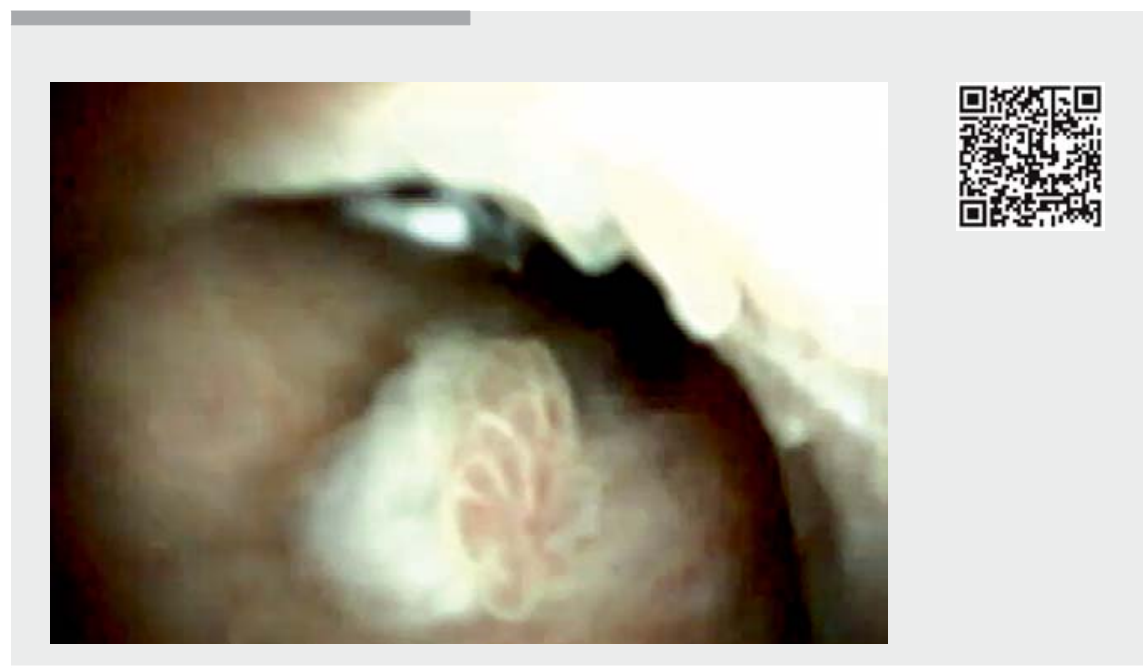

$\checkmark$ Video 1 Video showing the investigations and procedures performed in a 77-year-old man with acute-on-chronic pancreatitis, including abdominal ultrasound, endoscopic retrograde cholangiopancreatography, single-operator pancreatoscopy, and stone retrieval.

computed tomography scanning, and endoscopic ultrasound [1,2], the detection of neoplasia remains a diagnostic challenge in chronic pancreatitis. SOP offers a unique extension of the available techniques, through which even very small potentially malignant lesions of the MPD can be visualized and sampled. In this case, the PanIN-3 lesion was an incidental finding that led to resection of the premalignant polyp, thereby potentially preventing the development of pancreatic carcinoma $[3,4]$.

$$
\text { Endoscopy_UCTN_Code_TTT_1AR_2AI }
$$

\section{Competing interests}

Mark Ellrichmann and Alexander Arlt have received consultancy fees from Boston Scientific. All other authors have nothing to disclose.
The authors

Mark Ellrichmann ${ }^{1}$, Johannes Bethge ${ }^{1}$, Heiko Aselmann², Thomas Becker², Stefan Schreiber ${ }^{1}$, Alexander Arlt ${ }^{1}$

1 Interdisciplinary Endoscopy, Medical Department 1, University Hospital Schleswig-Holstein, Kiel, Germany

2 Department of General Surgery, University Hospital Schleswig-Holstein, Kiel, Germany

\section{Corresponding author}

Mark Ellrichmann, MD, PhD Interdisciplinary Endoscopy, Medical Department 1, University Hospital Schleswig-Holstein, Campus Kiel, ArnoldHeller-Str. 3, Haus 6, 24105 Kiel, Germany Fax: +49-431-50022378 mark.ellrichmann@uksh.de 


\section{References}

[1] Antonini F, Belfiori V, Pagano $\mathrm{N}$ et al. Endoscopic ultrasonography may select subjects having asymptomatic chronic pancreatic hyperenzymemia who require a stricter follow-up. Pancreas 2017; 46: $524-527$

[2] Issa Y, Kempeneers MA, van Santvoort HC et al. Diagnostic performance of imaging modalities in chronic pancreatitis: a systematic review and meta-analysis. Eur Radiol 2017; 27: 3820 - 3844

[3] Kirkegard J, Mortensen FV, Cronin-Fenton D. Chronic pancreatitis and pancreatic cancer risk: a systematic review and meta-analysis. Am J Gastroenterol 2017; 112: 1366-1372

[4] Moutinho-Ribeiro P, Coelho R, Giovannini M et al. Pancreatic cancer screening: Still a delusion? Pancreatology 2017; 17: 754 - 765

\section{Bibliography}

DOI https://doi.org/10.1055/a-0896-2405

Published online: 23.5.2019

Endoscopy 2019; 51: E288-E289

(c) Georg Thieme Verlag KG

Stuttgart · New York

ISSN 0013-726X

\section{ENDOSCOPY E-VIDEOS}

https:/|eref.thieme.de/e-videos

口回 Endoscopy E-Videos is a free Fection, reporting 回舴: on interesting cases and new techniques in gastroenterological endoscopy. All papers include a high quality video and all contributions are freely accessible online.

This section has its own submission website at

https://mc.manuscriptcentral.com/e-videos 